www.jmscr.igmpublication.org

Index Copernicus Value: 79.54

ISSN (e)-2347-176x ISSN (p) 2455-0450

crossrefDOI: https://dx.doi.org/10.18535/jmscr/v7i2.41

\title{
A Comparative Evaluation of Posterior capsular Opacification with Square Edged and Round Edged PMMA Intraocular Lens in Small Incision Cataract Surgery in rural areas of North Maharashtra
}

\author{
Authors \\ Dr Bandopadhyay Shweta', Dr Balwir Dheeraj ${ }^{2}$, Dr Mahadik Sanjay ${ }^{3}$ \\ ${ }^{1}$ Assistant Professor, Dept of Ophthalmology, Dr Vasantrao Pawar Medical College Hospital and Research \\ Centre, Adgaon, Nashik \\ Email: banerjee.shweta21@gmail.com \\ ${ }^{2}$ Professor, Dept of Ophthalmology, Dr Vasantrao Pawar Medical College Hospital and Research Centre, \\ Adgaon, Nashik \\ Email:dheeraj_balwir@yahoo.com \\ ${ }^{3}$ Assistant Professor, Dept of Ophthalmology. Dr Vasantrao Pawar Medical College Hospital and Research \\ Centre, Adgaon, Nashik \\ Email:drsanjay_m@yahoo.co.in
}

\begin{abstract}
Aim: To compare the incidence of Posterior Capsular Opacification (PCO) after implantation of Round Edged Polymethylmethacrylate (PMMA) IOL and Square Edged PMMA IOL in cases of Small Incision Cataract Surgery (SICS) and to select clinically significant cases of PCO for Neodymium-doped Yttrium Aluminum Garnet (Nd: YAG) capsulotomy.

Methods and Materials: A retrospective and comparative study in 500 eyes of 500 patients underwent uncomplicated SICS with Round Edged IOL implantation in group A and Square Edged IOL in group B with a minimal follow up period of 1 year. During this period the best corrected visual acuity and grades of PCO were assessed.

Statistical Analysis: Unpaired t test and Chi square test were used for statistical analysis.

Results: Overall incidence of visually significant PCO was $19.6 \%$,in group A the incidence was $29.6 \%$ and in group B it was $9.6 \%$.

Conclusion: This study showed that manual SICS with implantation of Square Edged IOL is a cost effective option for low income groups in rural areas. Square Edged design induces a barrier effect on PCO thereby reducing migration of lens epithelial cells and reducing incidence of PCO.PMMA supports epithelial cell adhesiveness to a lesser extent.
\end{abstract}

Keywords: Small incision cataract surgery (SICS), posterior capsular opacification (PCO), Round Edged Polymethylmethacrylate (PMMA) IOL, Square Edged Polymethylmethacrylate (PMMA) IOL.

\section{Introduction}

Cataract is a leading cause of blindness worldwide including India. In addition to the backlog, an additional 3.8 million become blind each year because of cataract. $^{[1]}$ Cataract surgery has evolved to modern day Phacoemulsification and Manual Small Incision Cataract Surgery. In a developing country like India, Manual Small 
Incision cataract surgeries with IOL implantation have been widely used. The modern day intraocular lenses used in SICS are posterior chamber standard PMMA Round Edged or Square Edged lenses. The most frequent long term complication of this surgery is Posterior Capsular Opacification with an overall incidence of $50 \% .^{[2]}$ Posterior capsular Opacification is the posterior migration of activated epithelial cells that leads to the formation of an opaque membrane on the posterior capsule. ${ }^{[3]}$ It causes a decrease in visual acuity by affecting the visual axis or by optical distortion. Decrease in visual acuity by more than 2 lines on Snellen's chart is considered visually significant. ${ }^{[4]}$ The development of PCO is a very dynamic process and involves three basic phenomena: Proliferation, Migration and Differentiation of residual Lens Epithelial Cells (LEC).Three Surgery related factors and three IOL related factors are particularly important in the prevention of PCO ${ }^{[5]}$ Surgery related factors to reduce PCO are hydrodissection enhanced cortical clean up, in the bag (capsular) fixation and capsulorrhexis edge on IOL surface.IOL related factors to reduce PCO are IOL biocompatibility, maximal IOL optic-posterior capsule contact and barrier effect of IOL optic.PCO disturbs fundus examination and optimal treatment by photocoagulation or vitrectomy in eyes with vitreoretinal disorders. PCO can be treated by Nd:YAG laser capsulotomy .It should be eliminated due to its deleterious sequelae and also Nd:YAG associated complications such as retinal detachment, endophthalmitis, rise in intraocular pressure, cystoid macular edema and damage to IOL.

Recent techniques worldwide being used are attempting to eliminate PCO development by improving surgical techniques, IOL materials, IOL designs, use of therapeutic agents and combination therapy. PCO is of great financial burden on the health care system and also patient follow up is difficult and at times Nd:YAG laser is not available. Thus the resolution of PCO is an urgent task in cataract surgery. Evidence strongly suggests that lens implant design rather than the lens material may be more important factor in prevention of PCO. ${ }^{[6]}$ Thus this study has been done to evaluate PCO after implantation of conventional Round Edged PMMA IOL versus Square Edged PMMA IOL in Manual Small Incision Cataract Surgery.

\section{Materials and Methods}

This retrospective and comparative study included 500 eyes of 500 patients who had undergone uncomplicated Manual small incision cataract surgery with posterior chamber intraocular (rigid PMMA Round or Square Edged) lens implantation by a single surgeon between July 2015 to July 2017 with a minimal postoperative follow up period of 1 year (Total study period July 2015 to July 2018).

Patients included in the study belonged to age group between 50 years to 70 years with mature or immature senile cataract, nuclear sclerosis grade I,II and III (LOCS III classification) with a minimum postoperative follow up of 1 year. ${ }^{[7]}$

Patients with comorbid conditions like corneal endothelial dystrophy, active inflammation, dense posterior subcapsular cataract, posterior polar cataract, pseudoexfoliation syndrome, glaucoma, ocular trauma, diabetes, intraoperative complications (posterior capsular rent, zonular dialysis and rhexis tear) and retinal pathology were excluded from the study.

This study was approved by the Local Institutional Review board and Ethics Committee. Informed consent was taken from all the patients for use of data for scientific publication. Preoperatively patients were evaluated for BCVA, Intraocular Pressure (IOP) measurement by Noncontact Tonometer, slit lamp biomicroscopy for grading of cataract and fundus examination to rule out retinal pathology. Routine Preoperative medical fitness was obtained.

Manual Small Incision Cataract Surgery was performed for all the patients with the same technique in both the groups. $6 \mathrm{~mm}$ superior sclera-corneal tunnel was made with a crescent 
blade. Anterior capsulotomy was done by Continuous Curvilinear Capsulorrhexis (CCC) technique. Cases where there was peripheral extension of the rhexis were converted into canopener technique. Hydrodissection was done and nucleus was prolapsed into the anterior chamber by visco-expression. Thorough irrigation and aspiration was done to avoid cortical remnants. Posterior capsular polishing was done.IOL was implanted in the capsular bag. Viscoelastic was aspirated with Simcoe's irrigation aspiration cannula. Anterior chamber was formed and sideport was sealed by stromal hydration. Antibiotic, steroid eye ointment was applied and pad and bandage was done.

Post cataract surgery treatment regime given was Gatifloxacin $0.3 \%$ eye drop and Prednisolone $1 \%$ eye drop in tapering dose for 1 month and Mydriatic eye drop BD for 15 days.

Characteristics of 2 IOL models used

Group I: Round Edged PMMA IOL, Length: 12.5, Optic diameter 6.00, A constant: 118.2, Modified ' $\mathrm{C}$ ' loop haptic.

Group II: Square Edged PMMA IOL, Length: $12.5 \mathrm{~mm}, 6.00 \mathrm{~mm}$, Aspheric optic, 360 degree square edge on $\mathrm{PC}$ side with $0.1 \mathrm{~mm}$ projected ridge, modified ' $\mathrm{C}$ ' loop haptic with $0.4 \mathrm{~mm}$ step vault.

Patients were followed up on $1^{\text {st }}$ day, 1 month, 6 months and 1year

At each follow up visit following parameters were evaluated: Best Corrected Visual Acuity (BCVA), slit lamp examination with dilated pupils for anterior segment evaluation to note cells, flare, left out cortical matter and grade of PCO by Sellman and Lindstrom grading system, ${ }^{[8]}$ intraocular tension by non-contact tonometer and fundus examination to evaluate the posterior segment.

Nd:YAG laser Capsulotomy was done in patients with visually significant PCO and presence of pearls or fibrosis type of PCO inside the IOL edge, reducing the red reflex. After laser treatment patients were prescribed Timolol $0.5 \%$ eye drop BD and Nepafenac $0.3 \%$ eye drop TDS for 7 days.
Patients were followed up after 7 days and 15 days at which BCVA, final refraction, IOP and fundus examination were done.

\section{Statistical Analysis:}

Statistical analysis was performed with the MedCalc version number 16.4.3 (Ostend, Belgium). Continuous variables were expressed as mean and standard deviation whereas categorical variables as percentage distribution. Normal distribution of data was assessed with Shapiro Wilktest. Pearson's Chi square test was used to compare the mean values of categorical variables. Continuous Variables were compared between 2 groups using Unpaired student " $t$ " test and paired student " $t$ " test for within group comparison. Statistical significance was reported at the $p<0.05$ *level.

\section{Result}

This study included 250eyes of 250 patients in each group operated between July 2015 to July 2017 with minimum follow up of 1 year. The mean age of patients at the time of cataract surgery was $65.3 \pm 8.2$ years in group 1 and $66.1 \pm 7.8$ years in Group 2. Group 1 included 135 male patients and 130 in Group 2. Mean preoperative BCVA in group 1 was $0.85 \pm 0.25$ and group 2 was $0.83 \pm 0.21$. The number of patients with immature and mature cataract were 190 and 60 in Group1 whereas 194 and 56 in Group 2 respectively. 200 patients underwent Anterior Capsulotomy by Continuous Curvilinear Capsulorrhexis and 50 patients by can-opener technique in Group1 while 201 patients underwent anterior Capsulotomy by Continuous Curvilinear Capsulorrhexis and 49 by can-opener technique in Group 2. There was no statistically significant difference in baseline characteristics $\mathrm{p}<0.05^{*}$ with respect to age, gender, preoperative $\mathrm{BCVA}$, grade of cataract and type of capsulotomies between the two groups. Postoperative mean BCVA at 1 month was $0.08+0.04$ in Group1 and $0.09 \pm 0.05$ in Group 2 which was not statistically significant. BCVA at 1 month: There was no PCO detected in either groups at 1 month. 
Postoperative mean BCVA at 6 month was 0.106 which was statistically significant. $(p=0.002)^{*}$ \pm 0.165 in Group1 and $0.071 \pm 0.115$ in Group 2

Table 1 BCVA at 6 Months

\begin{tabular}{|l|c|c|}
\hline BCVA LOGMAR & $\begin{array}{c}\text { Patients with Round } \\
\text { Edged IOL (N=250) }\end{array}$ & $\begin{array}{c}\text { Patients with Square } \\
\text { Edged IOL (N= 250) }\end{array}$ \\
\hline 0.0 & $160(64 \%)$ & $171(68.5 \%)$ \\
\hline 0.2 & $55(22 \%)$ & $70(28 \%)$ \\
\hline 0.3 & $15(6 \%)$ & $4(1.5 \%)$ \\
\hline 0.5 & $10(4 \%)$ & $3(1 \%)$ \\
\hline 0.6 & $10(4 \%)$ & $2(1 \%)$ \\
\hline
\end{tabular}

BCVA- Best corrected visual acuity

Group 2 which was statistically significant $(\mathrm{p}<$ Incidence of visually significant PCO (grade 4) at $0.001)^{*}$

6 months was $14 \%$ in Group1 while $3.5 \%$ in

Table 2: PCO at 6 Months

\begin{tabular}{|l|c|c|}
\hline Grade of PCO & $\begin{array}{c}\text { Patients with Round } \\
\text { Edged IOL (N= 250) }\end{array}$ & $\begin{array}{c}\text { Patients with Square } \\
\text { Edged IOL (N=250) }\end{array}$ \\
\hline I & $179(71.5 \%)$ & $224(89.8 \%)$ \\
\hline II & $20(8.2 \%)$ & $9(3.7 \%)$ \\
\hline III & $16(6.3 \%)$ & $8(7.5 \%)$ \\
\hline IV & $35(14 \%)$ & $9(8.75 \%)$ \\
\hline
\end{tabular}

Postoperative mean BCVA at 12 month was 0.148 \pm 0.227 in Group1 and $0.088 \pm 0.148$ in Group 2 which was statistically significant.

Patients who underwent Nd:YAG Capsulotomy at 6 months were excluded from further statistical analysis.

Table 3: $\mathrm{BCVA}$ at 12 Months

\begin{tabular}{|l|c|c|}
\hline $\begin{array}{l}\text { BCVA AT 12 Months } \\
\text { Logmar }\end{array}$ & $\begin{array}{c}\text { Patients with Round Edged } \\
\text { IOL }\end{array}$ & $\begin{array}{c}\text { Patients with Square Edged } \\
\text { IOL }\end{array}$ \\
\hline 0.0 & $129(60 \%)$ & $159(66.3 \%)$ \\
\hline 0.2 & $46(21.8 \%)$ & $67(27.5 \%)$ \\
\hline 0.3 & $5(2.2 \%)$ & $3(1.2 \%)$ \\
\hline 0.5 & $13(5.9 \%)$ & $6(2.5 \%)$ \\
\hline 0.6 & $13(6.1 \%)$ & $4(1.7 \%)$ \\
\hline 0.8 & $9(4 \%)$ & $2(0.8 \%)$ \\
\hline Total & 215 & 241 \\
\hline
\end{tabular}

Incidence of visually significant PCO (grade 4) at

Group 2 which was statistically significant.( P < 12 months was $18.2 \%$ in Group1 while $6.2 \%$ in $0.001)^{* * *}$

Table 4: PCO at 12 Months

\begin{tabular}{|l|c|c|}
\hline Grade of PCO & $\begin{array}{c}\text { Patients with Round Edged } \\
\text { IOL }\end{array}$ & $\begin{array}{c}\text { Patients with Square Edged } \\
\text { IOL }\end{array}$ \\
\hline I & $163(75.8 \%)$ & $222(92.2 \%)$ \\
\hline II & $8(3.6 \%)$ & $3(1 \%)$ \\
\hline III & $5(5 \%)$ & $1(0.6 \%)$ \\
\hline IV & $39(18.2 \%)$ & $15(6.2 \%)$ \\
\hline Total & 215 & 241 \\
\hline
\end{tabular}

Mean BCVA before Nd:YAG laser Capsulotomy was $0.34+0.18$ in Group1 and $0.33+0.20$ in Group2.

Mean BCVA after (2 weeks) Nd:YAG laser Capsulotomy was $0.08+0.09$ in Group1 and $0.07+0.08$ in Group2 which was not statistically significant between these two groups $(\mathrm{P}=0.78)^{\mathrm{NS}}$ The incidence of PCO at 6 and 12 months in can opener capsulotomy was statistically significant in both the groups. 
Figure1: Incidence of PCO in Each Group at 6 months

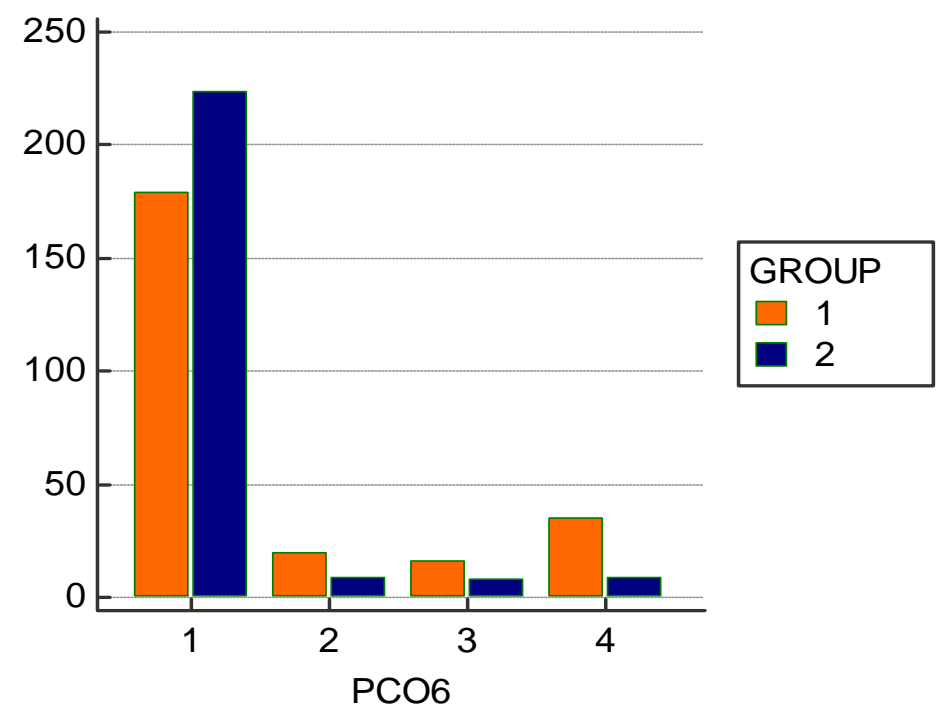

Figure 2: Incidence of PCO in each Group At 12 months

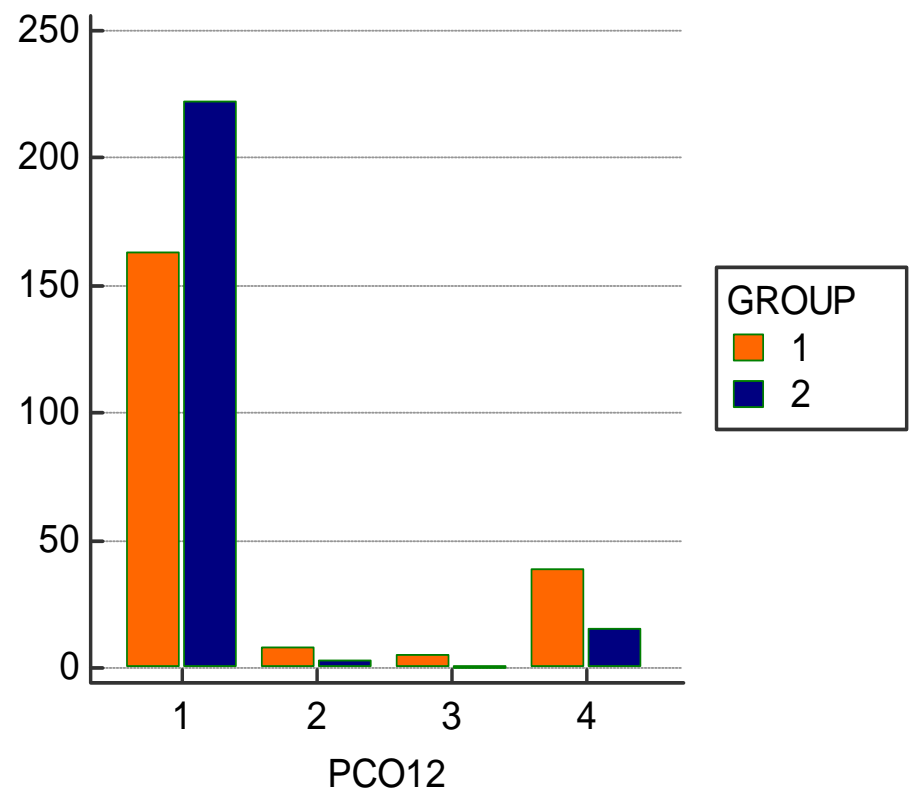

\section{Discussion}

In our study the overall incidence of visually significant PCO was 19.6\%.In Group A the incidence was $29.6 \%$ and in group B it was $9.6 \%$. Oner et $\mathrm{al}^{[9]}$ reported $24.7 \%$ PCO rates with PMMA IOL. Nagata et $\mathrm{al}^{[10]}$ in their study found grade 3 and grade 4 PCO in $4 \%$ of patients with sharp edged PMMA IOL implantation with CCC. In a study conducted by Shailly Raj et $\mathrm{al}^{[3]}$ clinically detectable PCO was present in $20 \%$ cases of round edged PMMA IOL and8\% cases of square edged IOL. Overall PCO rate was $14 \%$ while significant visual loss was seen in $12 \%$ cases. Goudinho et $\mathrm{al}^{[11]}$, in their study, showed an overall incidence of $\mathrm{PCO}$ with round edged PMMA IOL of $24 \%$ at 6 weeks, $31.3 \%$ at 6 months and $23.3 \%$ at 1 year compared to that with square edged PMMA IOL which was $5.4 \%$ at 6 week, $10,8 \%$ at 6 month and $7.6 \%$ at 1 year. Rekha et $\mathrm{al}^{[2]}$ reported $83.6 \%$ incidence of PCO, out of which $85.9 \%$ were in round edge PMMA IOL group and $81.2 \%$ were in square edge PMMA IOL group. $14 \%$ patients required $\mathrm{Nd}: Y A G$ capsulotomy at 6 months in Group A while $3.5 \%$ 
in Group B. At 12 months $.18 .25 \%$ patients required laser in Group A while $6.2 \%$ required it in Group B. Hollick et $\mathrm{al}^{[12]}$ reported $14 \%$ Nd:YAG laser capsulotomy rate with PMMA IOL after 2years follow up .Oner et al ${ }^{[9]}$ reported 26.3 $\%$ Nd:YAG capsulotomy rate with PMMA IOL after a mean follow up of 17.8 months. Nine years Nd:YAG capsulotomy rates in a study undergone by Aravind Haripriya et al ${ }^{[13]}$ were $2 \%$ for square edged PMMA IOLs versus $37 \%$ for round edged PMMA IOLs while it was $4 \%$ for square edged PMMA IOLs versus $10 \%$ for square edged Acrylic IOLs.

In this modern era advanced surgical technique like phacoemulsification has almost replaced manual small incision cataract surgery with a wide variety of IOL materials. Still India is a developing country with majority of its population dwelling in rural areas which does not have access to modern and costly equipments and IOLs. Our study is an attempt to find solution to this problem as we have used manual small incision cataract surgery as our technique and implanted PMMA IOL which is cost effective. Apart from this, Square Edged PMMA IOL has a lower incidence of PCO. PCO has to be dealt with Nd:YAG laser capsulotomy which is again costly with a poor access in rural areas.

It has been observed that the design of an IOL contributes more significantly to PCO formation than the IOL material. Nishi et al ${ }^{[14]}$ compared sharp edged hydrophobic acrylic with round edged PMMA IOL and found that there was inhibition of LEC migration in sharp edged optic whereas in the round optic edged LECs could freely migrate into the posterior capsule centre. Gagandeep et $\mathrm{al}^{[15]}$ showed that the implantation of square edged PMMA and hydrophobic acrylic lens had similar outcome in pediatric cataract surgery and square edged PMMA lens has a significant cost advantage over hydrophobic acrylic lens. Thus these studies support our finding to prove that sharp optic edge design has a preventive effect on PCO.
Studies on biocompatibility of IOL by Sarbani et $\mathrm{al}^{[6]}$ concluded that leucocyte chemotaxis induced by IOLs is higher in acrylic and silicone IOLs as compared to PMMA. So PMMA may be considered safe as an IOL material. Auffarth et $\mathrm{al}^{[16]}$ reported that there was no difference in PCO development between three- piece and one-piece acrylic hydrophobic IOLs. In a study done by Rahmi Duman et $\mathrm{al}^{[17]}$ eyes with acrylic hydrophyllic IOLs were more likely to develop PCO than those with acrylic hydrophobic IOLs. The lens design (1-piece versus 3-piece and varying haptic angles) did not affect the $\mathrm{PCO}$ rate. Therapeutic agents have also been used to tackle PCO. Ismail et al ${ }^{[18]}$ performed an experimental study to note the prevention of secondary cataract by antimitotic drugs Mitomycin C $(0.2 \mathrm{mg} / \mathrm{ml})$ and 5 -fluorouracil $(50 \mathrm{mg} / \mathrm{ml}) .5$ fluorouracil showed a more potent inhibitory effect. Pandey et $\mathrm{al}^{[5]}$ developed the Perfect Capsule Device which permits cytotoxic agents to be delivered selectively to the capsular bag thus selectively targeting residual LECs. Malecaze et al ${ }^{[19]}$ provided a gene therapy approach to target LECs in the capsular bag by inducing therapeutic apoptosis by overexpression of proapoptotic genes.

\section{Conclusion}

Posterior capsular opacification is the most common postoperative morbidity which needs $\mathrm{Nd}$ :YAG laser capsulotomy which is a costly affair and not easily accessible in rural areas.So we conclude that cataract extraction by manual small incision cataract surgery with square edged Polymethylmethacrylate intraocular lens is cost effective for the rural population. PMMA was taken as the material of choice because of it supports LEC adhesiveness to a lesser extent, lower cost and less susceptibility to damage caused by laser. Square edged design improves contact between the posterior capsule and optic thereby reducing migration of lens epithelial cells from the periphery towards the centre of the capsule and reducing incidence of posterior capsular opacification. 


\section{References}

1. Minassian DC, Mehra V .3.8 million blinded by cataract each year: Projections from the first epidemiological study of incidence of cataract blindness in India. $\mathrm{Br}$ J Ophthalmol 1990;74:341-3.

2. Mudhol RR, Shetti SA, Dodamani DK. Square edge intra-ocular lens versus conventional round-edge intra-ocular lens in prevention of posterior capsular opacification: A randomized clinical trial.J SciSoc 2016;43:6-10.

3. Shailly Raj, Singh Brijesh, Ifsa Sami, Singh Sonali. The square edged IOLS lessen the need of Nd:Yag Capsulotomy : A study in rural population. International Journal of Research in Health Sciences.2015 April - June;3(2):326-330.

4. Legler UF, Apple DJ, Assia EI, Bluestein EC , Castaneda VE, Mowbray SL: Inhibition of posterior capsule opacification; the effect of colchicine in a sustained drug delivery system. J Cataract Refract Surg.1993 July; 19 ( 4) 462-70.

5. Pandey SK, Apple DJ, Werner L, Maloof AJ, Milverton EJ. Posterior Capsule Opacification: A Review of the Aetiopathogenesis, Experimental and Clinical Studies and Factors for Prevention .Indian J Ophthalmol 2004;52: 99-112.

6. Sarbani Hazra, Himangshu Palui, Vemuganti Geeta. Comparison of design of intraocular lens versus the material for PCO prevention. Int J Ophthalmol.2012 Feb;5(1):59- 63.

7. Chylack LT, Wolfe JK, Singer DM, et al. The Lens Opacities Classification System III. Arch Ophthalmol.1993;111(6):831836.

8. Sellman TR, Lindstrom RL.Effect of a planoconvex posterior chamber lens on capsular opacification from Elschnig pearl formation .J Cataract Refract Surg 1988; $14: 68-72$

9. Oner FH, Gunenc U, FerlielST.Posterior capsule opacification after phacoemulsification: Foldable acrylic versus poly (methylmethacrylate) intraocular lenses.J

Cataract Refract Surg 2000; 26:722-6

10. Nagata T, Watanbe I. Optic sharp edge or convexity: Comparison of effects on posterior capsule opacification .Jpn J Ophthalmol 1996;40:397-403.

11. Goudinho SJ, Deeba F, Jacob JM. Incidence of posterior capsular opacification after small incision cataract surgery with PCIOL implantation using biconvex round edged PMMA IOL and square edged PMMA IOL. International Journal of Medical and Applied Sciences.2013;2:46- 59.

12. Hollick EJ, Spalton DJ, Ursell PG, Meacock WR, Barman SA, Boyce JF. Posterior capsular opacification with hydrogel, polymethylmethacrylate and silicone intraocular lenses: Two-year results of a randomized prospective trial. Am J Ophthalmol 2000;129:577-84

13. Long-term Posterior Capsule Opacification Reduction with Square-Edge Polymethylmethacrylate Intraocular Lens: Randomized Controlled StudyHaripriya A., Chang D.F., Vijayakumar B., Niraj A., Shekhar M., Tanpreet S., Aravind S.(2017) Ophthalmology, 124 , pp. 295-302

14. Nishi O,Nishi K ,WickstromK.Preventing lens epithelial cell migration using intraocular lenses with sharp rectangular edges. J Cataract Refract Surg 2000;26;1543-9

15. Gagandeep SB, Grewal DS, Jagat R, Singla M, Pal S,Grewal S. Square edge polymethylmethacrylate intraocular lens design for reducing posterior capsule opacification following paediatric cataract surgery: initial experience. Clinical\& Experimental Ophthalmology 2008;36(7):625-630

16. Auffarth,GU,GolesCU,A,Becker, KA et al .Quantification of posterior capsule opacification with round and sharped geintraocular lenses. Ophthalmoly. 2003;110:772-780

17. Duman $\mathrm{R}$ et al. Effect of four different intraocular lenses on posterior capsule 
opacification. Int J Ophthalmol 2015;8(1): 118-121.

18. Ismail MM, Alio JL, Ruiz Moreno JM. Prevention of secondary cataract by antimitotic drugs: experimental study. Ophthalmic Res. 1996; 28(1):64 - 9.

19. Malecaze F, Couderc B, de Neuville S, Serres B, Mallet J, Douin-Echinard V, Manenti S, Revah F, Darbon JM. Adenovirus-mediated suicide gene transduction: feasibility in lens epithelium and in prevention of posterior capsule opacification in rabbits. Hum Gene Ther. 1999;10:2365-72. 